\title{
A Representação Social da "Doença dos Nervos” entre os Gêneros
}

\author{
Alda Batista de Oliveira ${ }^{1}$ \\ Antonio Roazzi \\ Universidade Federal de Pernambuco
}

\begin{abstract}
RESUMO - Este trabalho investigou, na classe popular (30 homens e 30 mulheres, entre 18 e 65 anos), a organização estrutural da representação social do conceito da "doença dos nervos" e como o gênero está associado a essa organização estrutural. Por meio da técnica de associação livre, como meio de acesso ao campo semântico das representações, obteve-se um total de 272 respostas, compostas por 86 tipos de expressões semânticas que, quando agrupadas de acordo com a similaridade de significados, originaram 22 categorias de análise. A análise dos significados da "doença dos nervos" demonstrou que a organização estrutural do conceito dessa doença comporta os traços e os valores culturais que caracterizam homens e mulheres, mostrando como a cultura também determina códigos diferenciados para extravasarem suas perturbações. Por seu caráter privado, as mulheres atribuem significados num sentido voltado para a interioridade mostrados mais pelo corpo, enquanto os homens, pelo seu caráter público, atribuem significados num sentido de exterioridade expressas pelo comportamento.
\end{abstract}

Palavras-chave: doenças mentais; doenças dos nervos; representações sociais; teoria das facetas.

\section{The Social Representation of the "Nervous Disease" according to Gender}

\begin{abstract}
This work investigated, in a working class sample (30 men and 30 women, from 15 to 65 years), the structural organization of the social representation of the concept of "nervous disease", and how gender is associated to such structural organization. A free association task was applied on all participants as a tool to get access to the semantic field of the representations and a total of 272 responses was attained, composed of 86 kinds of semantic expressions that, when grouped according to similarity of meaning, originated 22 analytical categories. The analysis of the meanings of the "disease of the nerves" demonstrated that the roles culturally attributed to men and women generate differences in the expression of the disturbances: while for women they are more expressed in the body, for men they are more expressed in the behaviour.
\end{abstract}

Key words: mental diseases; diseases of the nerves; social representations; facet theory.

Os homens constroem símbolos para dar significados às experiências vividas, baseados em princípios construídos dentro de uma realidade empírica social. Ao longo do tempo, em sua prática, o homem vai captando informações, articulando sentidos, produzindo símbolos para efetuar suas trocas. Por entender que a cultura é essencialmente um sistema simbólico ou uma configuração de sistemas simbólicos, pode-se afirmar que a dimensão simbólica dos seres humanos determina as ações sociais, na medida em que atribui e organiza os significados aos fenômenos.

A linguagem é uma dimensão fundamental da cultura. Ela é responsável pela apreensão, transmissão e realização dos saberes, e é por meio dela que se apreende as regras fundamentais da cultura. Assim como o parentesco e a organização social, a linguagem é um medidor básico na transmissão cultural (Jovchelovitch, 2001). Pela linguagem, os indivíduos expressam seus comportamentos e arranjos socioculturais, ou seja, a forma como os elementos simbóli-

1 Endereço: Rua Amaro Coutinho, 566, Encruzilhada, Recife, PE, Brasil 52040-050.E-mail: aldabat@ fir.br cos se inter-relacionam logicamente uns com os outros para formar um sistema total. As palavras exprimem a forma como as pessoas constroem o seu mundo de experiências e seus princípios conceptuais, traduzindo a lógica simbólica que determina as ações sociais (Frake, 1962).

As pessoas categorizam, classificam, conceituam e nomeiam as coisas, os fatos e as outras pessoas para se comunicarem com os outros, para atribuírem uma lógica e, conseqüentemente, compreenderem suas próprias experiências e o mundo que as cercam (Tyler, 1978), construindo suas experiências a partir da forma pela qual elas falam sobre isso. Dessa perspectiva, pode-se considerar a cultura, segundo Lave (1988), como uma linguagem em sentido amplo.

O entendimento da maneira como as pessoas categorizam e atribuem conceitos às categorizações é fundamental para determinarmos a natureza dos conceitos nas relações sociais. Para tanto, se faz necessário considerar a origem e o conteúdo das expressões empregadas, como forma de ascendermos aos seus sentidos e significados pois, de fato, o significado que o indivíduo possui do mundo a sua volta é construído sobre uma rede de categorizações (Roazzi, Federicci \& Carvalho, 1999).

Ao elaborarem intersubjetivamente categorias de entendimento, as pessoas exprimem a conceituação do mundo, as maneiras de ação dentro de campos de signi- 
ficação (Roazzi, 1995) que, por sua vez, vão expressar as características culturais que servirão de referência para a identificação social. É na vida cotidiana que os indivíduos pensam e repensam, reformulam e reconstroem suas noções de entendimento, seus pressupostos de análise, seus padrões de comportamento, seus modelos explicativos do que é considerado saúde/doença, normal/anormal, masculino/feminino, atribuindo significados para se auto definirem e definirem o outro. Esse processo se dá nas trocas sociais, e mais precisamente pela comunicação social.

Assim, a construção da identidade social dos indivíduos se processa na vida cotidiana, por meio do cumprimento de tarefas que compõem suas rotinas e papéis instituídos e que, por sua vez, vão manter a realidade que é internalizada (Berger \& Luckmann, 1983), indicando "a criação inteiramente social das idéias, sobre os papéis próprios aos homens e mulheres" (Scott, 1996, p. 02), que são absorvidos pelo processo de internalização primária, como descritos por Berger e Luckmann (1983), e que são partilhados socialmente, confirmando "uma maneira de se referir às origens exclusivamente sociais das identidades subjetivas dos homens e mulheres" (Scott, 1996, p. 02).

$\mathrm{Na}$ totalidade social, as pessoas constroem seus códigos de identificação, suas identidades na relação com o outro por um processo dinâmico e mutável de construção do eu, composto de elementos individuais ou psicológicos e sociais, que se expressam na medida em que há a vivência de um sentimento de pertença e ao mesmo tempo de estranhamento, de diferenciação, do grupo que participa. Essa diferenciação torna o indivíduo autônomo, sujeito e ator social. Nessa perspectiva, "a identidade é a representação do ator social, do eu, um fenômeno cognitivo em que o ator social, o eu, é o objeto de conhecimento" (Andrade, 1998, p. 142).

A identidade do nervoso pode ser considerada como um bom exemplo da representação da organização ou estrutura do eu, dada pelo senso comum, aos conhecimentos adquiridos sobre os fatos, atos, necessidades e situações, as mais diversas, que compõem a vida cotidiana e que se encontram em estado insatisfatório para os indivíduos. Considerando que os objetos dos quais se apropriam os indivíduos, como o conceito da doença dos nervos, têm suas atribuições sociais de sentidos, articulados e construídos, na representação e pela linguagem (Moscovici, 1978, 1989), entende-se que nesse processo é o próprio indivíduo que, nas relações sociais, define-se e se circunscreve.

Com efeito, representar ou se representar corresponde a um ato de pensamento pelo qual um sujeito se relaciona com um objeto (Jodelet, 1989), como o conceito da doença dos nervos, justificando a importância de seu estudo, na medida em que, ao constituir uma maneira de traduzir os significados atribuídos aos mal-estares ou as insatisfações das pessoas em relação a diversos aspectos de suas vidas, possibilita uma aproximação desse conhecimento pela visão de gênero.

Um dos grandes desafios enfrentados perante a situação de sofrimento humano é a necessidade de compreensão dos modos pelos quais as pessoas exprimem os sentidos atribuídos à vivência da situação de doença. Estudos em saúde, sob o prisma sociocultural, reconhecem que a doença se constitui de significação. Enquanto categoria de entendimento, a doença pode ser definida como o conjunto de sensações ou sintomas, físicos ou mentais, interpretados como desconforto, que são organizados em uma totalidade dotada de sentidos e tem sua construção no processo de socialização (Alves \& Rabelo, 1998).

As representações sociais, segundo Minayo (1995, p.108), "são imagens construídas sobre o real" e se manifestam por meio da linguagem, dos sentimentos e das condutas, entretanto, sua mediação privilegiada é a linguagem.

Os grupos sociais constroem noções de saúde e doença, formam categorias de sintomas e nomeiam-na, baseados em princípios próprios de suas compreensões que orientam e organizam as condutas e as comunicações sociais. Formam um corpo de conhecimento composto por significados provenientes da realidade social dos sujeitos e que se expressam em códigos ou conceitos que aglutinam o entendimento social sobre aquela situação, contendo atribuição de causas, noções de práticas terapêuticas e sinais de identificação próprios da sua cultura. Assim, a concepção das doenças ou a sua representação é passível de diferentes interpretações, conforme o contexto social do qual se fala, mas também conforme o lugar e a situação do indivíduo dentro do grupo, ou seja, as sensações, sinais e sintomas corporais ou nãocorporais atribuídos às doenças, devem ser lidas de acordo com códigos de linguagem também específicos a quem fala, e que por eles se traduz.

A "doença dos nervos" vem sendo investigada sob diversas perspectivas teórico-metodológicas, pelas quais se buscam os fatores causais, sua provável correlação de gênero, assim como o seu significado, gerando uma diversidade de resultados, caracterizados por semelhanças e diferenças sobre o sentido do objeto.

Alguns autores investigaram a importância do contexto familiar e do trabalho, como fatores causais da "doença dos nervos" em mulheres. Paula e Scott (1985), procurando entender os significados do "nome dado pelas pacientes psiquiátricas do Recife, ao conjunto de seus sintomas psíquicos" (p. 332), analisaram a influência do controle paterno, como criador de situações de duplo vínculo, e a sobrecarga de trabalho das mulheres, expresso principalmente no cumprimento da dupla jornada (trabalho doméstico e extra-doméstico) no desenvolvimento da doença mental.

Hita (1998), em seu estudo sobre a identidade feminina e nervoso, conclui, a partir de relatos de mulheres pobres da periferia de Salvador, que a forma de interpretar e as questões inerentes ao curso da doença "parece ser bastante específico a sua condição social e de experiência, e que não podem ser reduzidos às questões do gênero feminino em geral"' (p. 209).

Para Duarte (1986), a “doença dos nervos" é um modo de expressão de um modelo de pessoa físico-moral, das classes trabalhadoras, que segue uma lógica holística, servindo para expressar todos os sinais de insatisfação das pessoas a que são atribuídos sentidos de doença visto que, "os nervos são pensados como um meio de experiências, tanto físicas quanto morais" (Duarte, 1994, p. 85). Seu conceito distingue dois planos de envolvimento: o físico, "incluindo todas as doenças que acometem o organismo humano", e o moral, "referentes aos diversos comportamentos das pessoas" (p. 29), todavia, apesar dessa distinção entre esses dois planos, "segundo a lógica do nervoso, é possível que um evento 
físico tenha implicações morais, ou uma experiência moral ter implicações físicas" (p. 85), sem deixar de distinguir os dois planos envolvidos.

Segundo Duarte (1986), por possuir uma relação familiar de caráter complementar, a construção da identidade social de pessoa nervosa (masculina ou feminina) tem como eixo principal, as qualidades e características a eles associados, física, mental e moral para o ideal de "ethos" masculino visto que, o homem se afirma por sua força física encompassada pela obrigação moral de provedor da família, tanto de alimentos, quanto de respeito. Em decorrência, o não cumprimento das obrigações de marido, referentes ao universo privado da casa, e a estrutura exterior pública e social associada ao homem, comporta ambigüidades suficientes para promover-lhe comportamentos desviantes. Assim, para o homem, a fome seria uma causa de perturbação nervosa pela sua incapacidade de botar comida dentro de casa, como também a traição da mulher ou o comportamento imoral das filhas.

A mulher, em oposição ao homem, é qualificada como essencialmente frágil, interna, privada, da casa, pois o trabalho fora de casa é ilegítimo, o que a isenta de apresentar a ambivalência do homem (ser da casa e da rua). O trabalho doméstico não possui valor a não ser na sua ausência. O corpo da identidade feminina é constituído por sua capacidade moral, sua honra expressa sob a fidelidade conjugal, responsabilidade pelo desenvolvimento dos filhos, pela reprodução (que é vista como uma obrigação que lhe produz respeito). Assim, não há nenhuma ênfase em suas capacidades físicas e mentais. A mulher pode se inquietar com a possibilidade de perder a situação de ser casada, modelo a ela destinado, gerando perturbações.

Considerando que as especificidades da natureza biológica dos corpos, ou diferenças naturais da forma e função corporal, determinaram ao longo da história espaços de atuação público para o homem e privado para a mulher, pressupomos que a significação que compõe a estrutura do conceito da "doença dos nervos" entre os gêneros reflete a diferenciação de universos e experiências vividas, bem como os critérios coletivos estabelecidos para utilização de seus corpos. Ou seja, que em suas representações sobre a doença dos nervos podem ser encontrados significados peculiares à condição de gênero.

Concordando com a posição de Duarte (1986), de que o campo de significação da "doença dos nervos" reflete a concepção de pessoa e expressa um modelo de pessoa físico-moral, propomo-nos a confirmar seu trabalho de investigação dos significados atribuídos ao conceito da doença dos nervos, por meio da utilização de uma outra abordagem empírica, como também ampliá-lo, no que tange ao prisma de gênero, buscando distinções na atribuição de significados desse conceito, entre os universos masculino e feminino. Tomando como referência as qualidades e características a eles associados, procurou-se averiguar a possibilidade de maior utilização de um, entre esses dois planos do modelo físico-moral, para expressar os sintomas da doença dos nervos entre os gêneros.

\section{Perspectiva teórico-metodológica}

Sobre as bases do conceito de representações coletivas de Durkheim, Serge Moscovici formulou a teoria das repre- sentações sociais, desenvolvendo uma nova interpretação dos fenômenos de representação social. Moscovici $(1978,1996)$ chamou-as de representações sociais por considerar que a sociedade moderna é muito complexa, diversificada, sofrendo constantes mudanças, julgando mais adequado atribuir a expressão coletiva às sociedades mais simples e homogêneas, como as estudadas por Durkheim (1912). Outra razão para esta mudança terminológica foi a concepção de que, apesar das representações serem elaboradas nos processos de comunicação sobre todos os fenômenos que permeiam a interação dos indivíduos, elas não são homogêneas nem tampouco partilhadas por toda a sociedade, uma vez que são formadas dentro de condições socialmente desiguais resultantes da divisão do trabalho. Moscovici caracteriza as representações sociais como um processo criativo (de elaboração cognitiva e simbólica) que serve de orientação ao comportamento das pessoas, por considerar que esse aspecto, inexistente na concepção de Durkheim, revela o fenômeno de reprodução do pensamento. Ao enfatizar as comunicações de massa, Moscovici infere a possibilidade de se considerar as representações como um fenômeno capaz de explicar como o novo é engendrado nos processos de interações sociais e, inversamente, como se produzem as representações sociais. A teoria das representações sociais de Moscovici tem, portanto, uma função agregadora na visão indivíduo-sociedade, principalmente quando se refere à posição de Durkheim, que distinguia os estudos das representações individuais (considerando-as áreas de conhecimento da Psicologia) dos estudos das representações coletivas (considerando-as área da sociologia), observando que o conceito de representação social é semelhante na antropologia e na sociologia. Moscovici relativiza sua análise, por acreditar que há uma reciprocidade entre os fenômenos psicológicos da vida social e cultural.

A Teoria das Representações Sociais demonstra a importância primordial da comunicação nos fenômenos representativos, visto que é por meio dela que se transmite a linguagem, que por ela mesma é portadora de representações sociais e culturais.

A concepção de pessoa "doente dos nervos", como se refere Duarte (1986), da perspectiva da teoria das representações sociais, pode ser concebida como mediadora na elaboração e expressão de elementos provindos das realidades tanto objetivas quanto subjetivas dos sujeitos, no que tange a essa enfermidade, visto que, as representações sociais da saúde, enquanto fenômenos cognitivos, envolvem a pertinência social dos indivíduos com suas implicações afetivas e normativas, com as interiorizações de experiências, de práticas, de modelos de condutas e de pensamento, socialmente inculcados ou transmitidos pela comunicação social, que a eles estão ligados (Jodelet, 1989).

As representações sociais, por serem elaboradas na fronteira entre o psicológico e o social nos processos de trocas sociais, são capazes de estabelecer conexões entre as abstrações do saber e das crenças e a "concretude" da vida do indivíduo em seus processos de troca com os outros, permitindo articular os aspectos objetivos e concretos da vida das pessoas com os aspectos simbólicos, e proporcionando ao pesquisador superar dicotomias entre o psicológico e o social. 
Por ser uma abordagem do tipo psicossocial, a Teoria das Representações Sociais parte do pressuposto que, para a compreensão das ações humanas, faz-se necessário considerar tanto as estruturas e organizações cognitivas e suas formas de interação e combinação quanto o conteúdo e as origens sociais das identidades. Presume que a realidade é percebida por um recorte, uma dimensão dela mesma, nunca em si mesma, pressupondo que a atividade simbólica é o grande articulador desse recorte, feito a partir dos sonhos, crenças, sensações, em que emoções e afetos emergem como mediadores tão significativos quanto pensamento e linguagem, ou os processos grupais (Roazzi, 1987a).

A elaboração da representação social é claramente assinalada pela linguagem, pois ao categorizar e nomear o mundo se organiza, os objetos se materializam. Desta forma, consideramos importante enfocar nesses estudos, quais objetos ou fatos sociais as pessoas representam e como se dá essa representação. Ademais, por sua função agregadora, também é importante procurar compreender por quê, e para que, as representações sociais de um determinado objeto são construídas de determinada forma, por entender que dessa perspectiva emergem de forma nítida os sentidos dos processos de simbolização e da atividade cognitiva em relação aos significados que o mundo externo assume ao nível da vida psíquica (Roazzi, Wilson \& Federicci, 1995, 2001).

Uma questão importante se coloca: em pesquisas sobre representações sociais, os instrumentos interpretativos são considerados mais adequados para explorar as estratégias pelas quais as pessoas categorizam e elaboram sistemas de classificação. Entretanto, essas classificações, em geral, são construídas a partir de categorias formuladas pelo próprio pesquisador e não da perspectiva dos sujeitos.

Os estudos antropológicos da abordagem cognitiva presumem que o entendimento da maneira como as pessoas categorizam e atribuem conceitos às categorizações é fundamental para determinarmos a natureza dos conceitos e a organização desses pelas pessoas nas relações sociais. Partem da perspectiva que, para se compreender como as pessoas percebem o mundo que as cerca, é necessário entender como estas chegam aos julgamentos das categorias e conhecer os processos de origem destas, pressupondo que as pessoas constroem representações cognitivas a respeito das suas experiências.

A forma de se chegar à origem das categorias sociais da perspectiva dos sujeitos é por meio da análise da estrutura dos conceitos por eles empregados para denominarem os fatos, denominarem-se, comunicarem-se e assim construírem um conhecimento, uma imagem elaborada socialmente, utilizando-se instrumentos mais adequados como os estruturados e os associativos (Russel, 1994). O conceito de estrutura aqui utilizado reflete a relação entre as categorias ou expressões semânticas usadas pelas pessoas para expressarem o entendimento que têm sobre um objeto social, dentro de uma determinada cultura.

\section{O estudo}

$\mathrm{Na}$ busca de entender as experiências humanas de insatisfações e sofrimentos, sejam provocadas pela condição de vida ou pela maneira de compreender os fatos, procuramos neste trabalho investigar, na classe popular, a organização estrutural da representação social do conceito da "doença dos nervos" e como a variável gênero está associada a essa organização estrutural.

Por se tratar de um estudo com uma preocupação "êmica" (Roazzi, 1987b), optou-se por investigar empiricamente a organização estrutural da representação social deste conceito pelo levantamento do campo semântico, numa perspectiva teórico-metodológica que se baseou no paradigma das representações sociais (Moscovici, 1978) e em estudos antropológicos que usam análises multidimensionais, tomando como ponto de partida os métodos e técnicas da antropologia cognitiva ${ }^{2}$ (D’Andrade, 1995; Roazzi, 1995; Russel, 1994) e planejado com base na Teoria das Facetas (Borg, 1979, 1993; Canter \& Kenny, 1981; Dancer, 1990; Donald, 1985; Feger \& Von Hekher, 1993; Guttman, 1965; Levy, 1985, 1993).

A Teoria das Facetas visa integrar a teoria com o planejamento da investigação e seus procedimentos e técnicas de coleta, análise e interpretação dos dados (Roazzi, 1999a; Roazzi \& Dias, 2001). Concebendo a realidade social como uma complexa rede de interação de diversas variáveis, a Teoria das Facetas, de modo semelhante, trata o estudo dos conceitos como um grupo de componentes inter-relacionados. Essa Teoria propõe procedimentos que permitem identificar os componentes conceituais e como esses componentes se relacionam entre si, por meio de uma apresentação figurativa, de forma espacial, dos elementos que compõem o conceito, permitindo que se façam inferências sobre a natureza empírica do conceito investigado. Como procedimento de coleta de dados utilizou-se a aplicação das técnicas de associação livre e entrevista semi-estruturada, e os dados foram submetidos à interpretação e análise segundo o SSA (Similarity Structure Analysis) (para maiores detalhes destas análises ver Roazzi, 1995, 1999b; Roazzi \& Monteiro, 1995; Roazzi, Loureiro $\&$ Monteiro, 1996).

\section{Método}

\section{Amostra}

Foi investigada uma amostra de 60 sujeitos, moradores de uma comunidade da classe popular, composta de 30 homens e 30 mulheres, com idades entre 18 a 65 anos. Todos os participantes sabiam ler e escrever, com uma permanência de pelo menos dois ou três anos na escola. Utilizou-se como material para a coleta de dados deste trabalho protocolos para anotação dos dados pessoais dos sujeitos e um roteiro de entrevista semi-estruturada contendo sete perguntas para assim desencadear a expressão do conhecimento dos sujeitos sobre a doença de nervos.

Para composição da amostra, foram empregados os seguintes critérios:

- O critério geográfico - que significou a escolha aleatória de três ruas, em cada uma das quatro áreas da comunidade, perfazendo um total de 12 ruas escolhidas por área e 48 ruas

2 Russel, em seu livro Research Methods in Anthropology: Qualitative and Quantitative Approaches, mostra que estes são métodos e técnicas bastante usados em antropologia cultural há mais de 20 anos. 
no total. Em cada duas ruas, por área, dois homens e duas mulheres eram abordados e na terceira rua abordou-se um homem e duas mulheres ou dois homens e uma mulher, de forma que ao final da coleta por área, foi possível perfazer um total de 15 sujeitos.

- Condições físicas da moradia - visitaram-se, em cada rua, casas em diferentes estados de conservação e construções diferentes, ou seja, de alvenaria e do tipo barraco.

- Critério de horário - a coleta aconteceu durante o período da manhã e no período da tarde durante os dias úteis da semana e aos sábados e domingos para que pudessem ser encontradas as pessoas que trabalham fora da comunidade.

\section{Procedimento}

Para se chegar aos participantes desta investigação foi estabelecido, inicialmente, contato com o posto comunitário de saúde. Muitas das informações sobre a comunidade foram fornecidas pelas agentes de saúde e pessoas que procuravam os serviços do posto, bem como pelos comerciantes do mercado público.

Os participantes foram abordados individualmente, em suas casas, em seus estabelecimentos comerciais ou na rua e solicitados a colaborarem com uma pesquisa da Universidade Federal de Pernambuco (UFPE). Nenhuma informação sobre o objeto de investigação, o objetivo da pesquisa, foi fornecida antes de se coletar os dados por meio da técnica de associação livre, em que os sujeitos foram solicitados a expressarem de forma livre e instantânea as palavras que lhe ocorressem, que se passassem em suas mentes, mediante a evocação da expressão "doença dos nervos", de acordo com a seguinte instrução: "Diga, o mais rápido possível, todas as palavras que passam pela sua cabeça quando você pensa na 'doença dos nervos". . Não houve limitação de tempo para a execução dessa tarefa e, em todos os casos, após a compreensão da instrução, as respostas foram fornecidas com muita rapidez, num tempo médio de um minuto.

Apesar de termos escolhido sujeitos alfabetizados, com o intuito de pedir que escrevessem uma lista de palavras, na aplicação dessa técnica, e apesar de termos se encontrado muitas pessoas com nível de escolaridade secundário, decidiu-se que a própria entrevistadora anotaria as respostas que fossem dadas para evitar que algumas palavras fossem omitidas, por conta de muitos sujeitos terem dificuldades em escrevê-las e desta forma se controlar uma possível variável, uniformizando o procedimento de coleta.

Alguns participantes apresentaram dificuldades no entendimento das instruções para realização dessa técnica. Nestes casos, a pesquisadora apresentava um exemplo, utilizando uma palavra qualquer e algumas possíveis palavras e expressões que poderiam ser a ela relacionadas. Por exemplo, a palavra festa. A pesquisadora explicava: "Se eu lhe dissesse a palavra festa, você poderia me responder que festa lhe lembra música, alegria, bebida, brigas, conversa, etc.".

Além da associação livre, utilizou-se também como material para a coleta de dados protocolos para anotação dos dados pessoais dos participantes e um roteiro de entrevista semi-estruturada contendo seis perguntas para desencadear a expressão do conhecimento dos sujeitos sobre a "doença de nervos". As perguntas feitas foram: 1) Você já ouviu falar da “doença dos nervos"? 2) Que tipo de pessoa pode sofrer dessa doença? 3) O que leva você a perceber que uma pessoa sofre dos nervos? 4) O que leva uma pessoa a sofrer dessa doença? 5) O que deve ser feito para se livrar dessa doença? 6) Você conhece alguém que deixou de ter essa doença? Devido a problema de espaço neste artigo serão apresentados somente os resultados da Associação Livre.

\section{Resultados}

A primeira etapa da análise dos dados foi a listagem de todas as palavras e expressões fornecidas pelos sujeitos na aplicação da técnica de associação livre. Essa listagem resultou na obtenção de 272 expressões, das quais 148 foram fornecidas pelas mulheres e 124 pelos homens, ficando uma média de 4,5 respostas por sujeito. Essa etapa do processo de análise dos resultados já permitia verificar empiricamente a existência de 86 tipos de categorias na representação social da "doença dos nervos", as quais, ao serem agrupadas de acordo com a similaridade de significados, originaram 22 categorias de análise. O julgamento de similaridades de significados das categorias seguiu os dois critérios ou indícios (sintomas físicos e sintomas morais) apontados por Duarte (1986) como constituintes da significação do conceito. Ao final desse processo, obtiveram-se três grupos de categorias: os sintomas morais (apresentou o maior número de respostas), os sintomas físicos e acrescentaram-se os fatores causais.

Foram considerados como sintomas físicos aqueles que se apresentam mais evidentes no corpo. Em oposição, consideraram-se sintomas morais aqueles mais perceptíveis pelo comportamento. Para denominar as categorias, seguiram-se alguns critérios, como: a expressão que apresentou o maior número de respostas emprestou o nome à categoria; ou escolheram-se aquelas que possuíam um sentido englobante das demais. Observamos que a construção dessas categorias procurou privilegiar o consenso quantitativo e qualitativo dos dados, de acordo com a metodologia que foi empregada. Os sintomas que disseram respeito às características físicas foram referidos por 18 expressões diferentes e mais da metade destas apresentou apenas uma resposta. Isso levou a uma nova categorização, baseado no critério de similaridade do sintoma, como por exemplo "tremor", "tremedeira" e "voz trêmula" compôs a categoria "tremedeira".

A Tabela 1 apresenta 1) as categorias alocadas sob os três critérios, sintomas físicos, sintomas morais e as causas associadas ao conceito da doença dos nervos e 2) a porcentagem das respostas fornecidas pelo gênero feminino, pelo gênero masculino.

Conforme mostra a tabela, oito categorias apresentaram sintomas e aspectos físicos associados a "doença dos nervos". Em sua totalidade, as categorias que compõem o grupo de sintomas físicos foram mais referidas pelo gênero feminino do que pelo gênero masculino. Destas se destacam as categorias "caretas", "choro" e "dores" (composta pelas expressões "dor de barriga" e "dor de cabeça"), por terem sido referidas apenas pelo sexo feminino.

O grupo de categorias referente aos sintomas morais apresentou o dobro do número de respostas que os outros dois grupos. Também se observa uma diferença de mais de 10\%, no total de respostas deste grupo, em favor das mulheres. Essa 
Tabela 1. Porcentagem de cada categoria por cada grupo (feminino e masculino).

\begin{tabular}{|c|c|c|c|}
\hline \multirow[t]{2}{*}{ Categorias } & \multicolumn{3}{|c|}{ Gêneros } \\
\hline & Feminino & Masculino & Total \\
\hline \multicolumn{4}{|l|}{ Sintomas Físicos } \\
\hline Ataque & 1.10 & 0.74 & 1.84 \\
\hline Caretas & 1.10 & 0 & 1.10 \\
\hline Choro & 1.47 & 0.37 & 1.84 \\
\hline Dores & 1.84 & 0.37 & 2.21 \\
\hline Insônia & 2.21 & 1.84 & 4.04 \\
\hline Náuseas & 0.37 & 0.74 & 1.10 \\
\hline Stress & 0.74 & 1.10 & 1.84 \\
\hline Tremedeira & 2.21 & 2.21 & 4.41 \\
\hline Total & 11.03 & 7.35 & 18.38 \\
\hline \multicolumn{4}{|l|}{ Sintomas Morais } \\
\hline Abandono & 0.74 & 1.47 & 2.21 \\
\hline Agitação & 6.62 & 6.25 & 12.87 \\
\hline Aperreio & 6.62 & 4.04 & 10.66 \\
\hline Decepções & 1.10 & 0 & 1.10 \\
\hline Descontrole & 3.31 & 1.10 & 4.41 \\
\hline Doença & 4.41 & 3.68 & 8.09 \\
\hline Medo & 6.62 & 3.31 & 9.93 \\
\hline Necessidades & 1.47 & 0.37 & 1.84 \\
\hline Nervosismo & 3.31 & 2.94 & 6.25 \\
\hline Total & 34.19 & 23.16 & 57.35 \\
\hline \multicolumn{4}{|l|}{ Causas } \\
\hline Alcoolismo & 0 & 2.21 & 2.21 \\
\hline Ambiente & 1.84 & 1.47 & 3.31 \\
\hline Nascença & 0.37 & 0.37 & 0.74 \\
\hline Problema Familiar & 1.47 & 2.21 & 3.68 \\
\hline Situação Financeira & 5.51 & 8.82 & 14.33 \\
\hline Total & 9.19 & 15.07 & 24.26 \\
\hline Total de respostas & 54.41 & 45,59 & 100,00 \\
\hline
\end{tabular}

diferença se eleva nas categorias "aperreio", "decepções", "descontrole", "medo" e "necessidades".

Para as respostas referentes às causas da "doença dos nervos", a porcentagem de respostas se mostrou maior em relação aos sintomas físicos, observando-se com uma diferença de mais de $10 \%$ em favor do gênero masculino. Essa elevação é produzida pela porcentagem de respostas nas categorias "alcoolismo", "problema familiar" e "situação financeira". No Apêndice encontra-se descrita, de forma detalhada, a análise qualitativa dos dados, tomando como referência, para apreensão dos significados dessas categorias, a contribuição de diversos autores, e em especial a de Duarte (1986).

Após a definição das categorias que conformam a estrutura do conceito, aplicou-se um novo tratamento aos dados, o SSA para se determinar o grau de inter-correlações dessas categorias entre si na composição da estrutura do conceito da "doença dos nervos". O SSA (Similarity Structure Analysis) é um subgrupo de um conjunto de análise de dados denominadas análises escalonares multidimensional (MDS), a partir do qual se retrata a estrutura de dados num modelo espacial, em que o elemento essencial da definição de todo método de escalonagem multidimensional é a representação espacial da estrutura de dados (Young, 1987). Essa análise constrói uma representação geométrica dos dados, usualmente em um espaço euclidiano, de dimensionalidade mínima. Esta análise constrói uma representação geométrica dos dados, usualmente em um espaço euclidiano, de dimensionalidade mínima, onde as categorias são representadas graficamente como pontos. Quanto mais próximas as categorias estiverem localizadas neste espaço (os pontos que as representam), maior a correlação entre elas e vice-versa (Guttman, 1968; Young, 1987). Em seguida utilizamos o método de variáveis externas como pontos (Amar \& Cohen, 1999; Roazzi \& Dias, 2001), para estabelecer a correlação existente entre a estrutura conceitual encontrada e os gêneros.
Antes de apresentar os resultados, visando melhor compreender a escolha das análises utilizadas nessa investigação, é importante ressaltar algumas preocupações teórico-metodológicas. Na perspectiva da Teoria das Facetas que adotamos neste estudo, visto que as variáveis não são concebidas como entidades discretas isoladas entre si, mas principalmente inter-relacionadas, o primeiro passo é estabelecer qual é a estrutura subjacente aos dados. Em nosso estudo, mais especificamente, esta estrutura relacional refere-se às categorias criadas a partir da associação livre. $\mathrm{O}$ segundo passo é verificar como as variáveis independentes (tratadas como variáveis externas nas análises multidimensionais) estão relacionadas com essa estrutura (não as variáveis dependentes isoladas). Esse segundo passo é um avanço em relação ao uso de técnicas de análises MDS clássicas. De fato estas têm sido questionadas por não serem capazes de lidar com sub-populações (Doise, Clémence \& Lorenzi-Cioldi, 1993). Essa técnica possibilita integrar sub-populações nos mapas ou projeções MDS, i.e., possibilita localizar espacialmente variáveis externas (os dois gêneros) como pontos na estrutura interna representada na projeção ou mapa SSA que, é importante sublinhar, permanece inalterada. Assim, no lugar de analisar diferentes mapas SSA, um de cada subgrupo, é produzido um único mapa integrado representando ao mesmo tempo a estrutura das categorias e os dois subgrupos - os dois gêneros (para melhores detalhes ver Roazzi, 1995 e Roazzi \& Dias, 2001). A Figura 1 resume essas duas análises empreendidas, apresentando a representação espacial da organização estrutural do conceito da "doença dos nervos" e sua inter-relação com as variáveis externas gênero masculino e gênero feminino.

A organização estrutural do conceito apresentou uma configuração do tipo axial composta por três regiões distintas. Na parte inferior esquerda, localizaram-se as categorias relacionadas aos sintomas físicos, na parte intermediária, as 


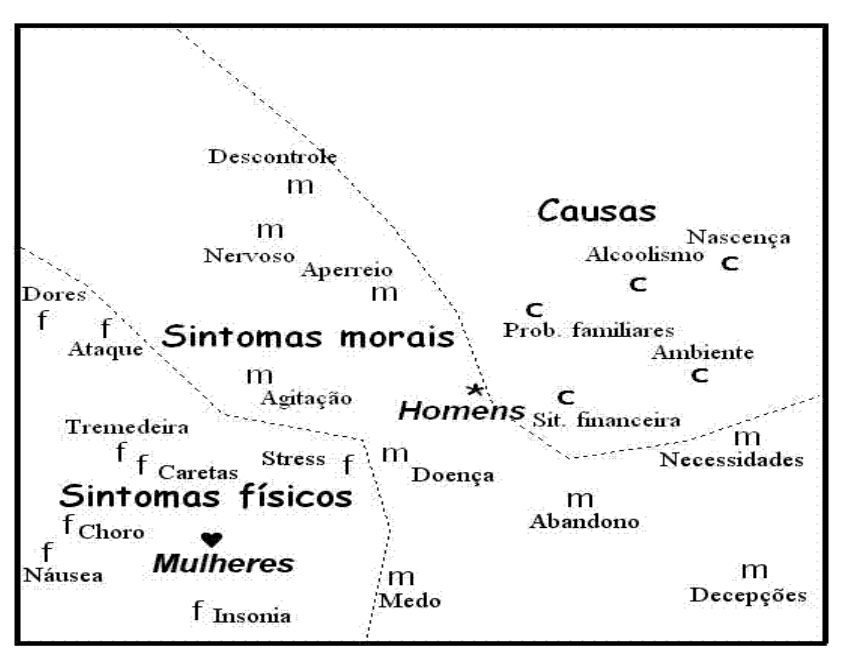

Figura 1. Análise SSA das categorias sobre a doença dos nervos considerando como variáveis externas homens e mulheres (Coordenada 1 versus 2 da análise tridimensional, Coeficiente de alienação: 0.16).

categorias referentes aos sintomas morais e na parte superior, as categorias alocadas como causas.

Com relação aos gêneros, o sexo feminino aparece bem no centro do agrupamento de sintomas físicos, enquanto o sexo masculino situou-se numa posição intermediária entre os sintomas morais e os fatores causais.

No grupo de sintomas físicos, a "tremedeira", as "caretas" e o "stress", mostram-se bastante associados entre si e mais próximos do "choro" e das "náuseas". A "insônia" aparece isolada dos demais sintomas, enquanto as "dores" e o "ataque", bastante interrelacionados, colocam-se distantes das demais categorias.

No grupo dos sintomas morais, intermediário na configuração, percebe-se uma maior inter-correlação entre o "descontrole", o "nervoso" e o "aperreio", enquanto as demais categorias denotam uma correspondência mais tênue entre si, como a "agitação" e a "doença", o "medo", as "necessidades", o "abandono" e as "decepções".

$\mathrm{Na}$ parte superior, onde se colocam os sintomas causais, observamos duas correlações: uma entre "situação financeira" e "ambiente" e outra entre "alcoolismo" e "problemas familiares". A categoria "nascença" aparece isolada das demais. Ainda podemos observar correlações das categorias entre os três grupos: a "tremedeira", as "caretas" e o "stress" aproximam-se da "agitação" e da "doença", assim como o "medo" da "insônia". Também mostram uma maior correlação entre grupos, as categorias "situação financeira" e "necessidades".

De acordo com os resultados apresentados, pode-se afirmar que o gênero feminino se utiliza mais de sintomas físicos, como as "caretas", o "choro" e as "dores", para representar socialmente seu mal-estar e perturbações, do que o gênero masculino, enquanto o gênero masculino se utiliza mais dos sintomas morais e fatores causais, como o "alcoolismo", a "situação financeira", a "agitação" e o "aperreio" para expressar suas insatisfações.

Pode-se ainda acrescentar que os sintomas físicos das mulheres como a "tremedeira", as "caretas" e o "stress" apa- recem associados a um quadro de "agitação" e de "doença", assim como a "insônia" das mulheres está muito relacionada a um estado de "medo". Como também podemos ressaltar que o estado de "abandono", a que se referem os homens, está relacionado com a sua "situação financeira".

\section{Discussão e Conclusão}

O interesse principal desta pesquisa foi investigar, na classe popular, a organização estrutural da representação social do conceito da "doença dos nervos" e a relação do gênero com essa estrutura, considerando que diversos estudos associam a "doença de nervos" ao gênero feminino, apresentando diversos argumentos à razão do fenômeno.

Nossa proposta de inovação metodológica provém de questionamentos sobre a criação das categorias de análises por meio dos métodos usualmente empregados nos estudos socioculturais, principalmente na área de representações sociais, por entendermos que, muitas vezes, categorias empregadas por um indivíduo, com uma história, gênero, tempo e lugar, são tomadas como representativas de um grupo.

Nosso objetivo foi verificar empiricamente a estrutura do conceito, por uma proposta metodológica geralmente utilizada em estudos "êmicos" na área da antropologia cognitiva, empregando critérios de análise que, segundo Duarte (1986), conformam a noção de pessoa, na classe popular, abarcando as dimensões física e espiritual, traduzidas em sintomas físicos-morais. Contudo, apesar de concordarmos com esse autor em que a ação de fatores causais provocam danos morais sobre o comportamento dos indivíduos, decidimos encarar as causas como um critério distinto dos demais. Essa decisão baseou-se no pressuposto de que, para apreendermos o entendimento que as pessoas possuem de um objeto, de seus saber sobre o objeto estudado, de suas racionalidades, faz-se necessário considerar o contexto social, suas características e princípios culturais, como afirma Jovchelovitch (2001).

Da perspectiva teórico-metodológica usada, que se diferencia dos autores citados (Duarte, 1986; Hita, 1998; Paula \& Scott, 1985), encontramos correspondência entre as categorias por eles apontadas e as encontradas pelo levantamento do campo conceitual, pela técnica de associação livre, o que proporciona um caráter de maior validade aos resultados. Mostramos que na representação social da organização estrutural da "doença dos nervos", numa configuração do tipo axial, composta por três distintas regiões, distribuem-se categorias dos três critérios utilizados: os sintomas físicos, os sintomas morais e os fatores causais, evidenciando a importância de utilizarem-se outras metodologias em pesquisas de representação social. Percebemos pela metodologia utilizada que a representação dessa estrutura diferencia-se de acordo com os gêneros, na medida em que as mulheres articularam a representação da doença enfatizando os sintomas físicos, enquanto os homens enfatizaram os sintomas morais e fatores causais.

Levando em conta os resultados apresentados, em que predominou uma significação de comportamento no gênero masculino, enquanto que as mulheres, referiram-se mais aos sintomas físicos, entendemos que os significados atribuídos a "doença dos nervos" estão fortemente relacionados aos fatores sócio-econômicos, mas também às experiências e 
vivências específicas aos gêneros. Como também podemos comprovar, segundo Guareschi (1995), a realidade entrevista por Moscovici (1989), ao afirmar que o conceito de representação social deve dar conta de uma realidade que compreenda as dimensões físicas, sociais e culturais.

Podemos dizer que, ao se apropriarem de uma imagem como a dos nervos para expressarem suas subjetividades, as pessoas se utilizam da linguagem para representarem suas insatisfações pessoais, conforme princípios culturais norteadores de suas identidades sociais, sobretudo de gênero e classe social. E mais, conforme o conceito de polifasia cognitiva, proposto por Moscovici (1989), diferentes tipos de racionalidade estão presentes num mesmo indivíduo, conforme a situação em que ele se encontra, como classe social e gênero (Jovchelovitch, 2001).

Ao elegerem os nervos num sentido mais físico, as mulheres podem demonstrar a prevalência de um referencial de pessoa, que conforma a noção de eu, de seu ser, remetido a aprendizagem de dores físicas provindas de suas vivências das funções reprodutivas e enfatizadas pela cultura. Contrariamente, ao se apropriarem da dimensão moral, os homens parecem ancorar-se numa permissividade social para a expressão de seus comportamentos.

Concluímos que, a organização estrutural do conceito da "doença dos nervos" comporta os traços e os valores culturais que caracterizam homens e mulheres, mostrando como a cultura também determina códigos diferenciados para extravasarem suas perturbações. Por seu caráter privado, as mulheres atribuem significados num sentido voltado para a interioridade, que se mostram mais pelo corpo, enquanto os homens, pelo seu caráter público, atribuem significados num sentido de exterioridade que se expressam pelo comportamento.

\section{Referências}

Alves, P. C. \& Rabelo, M. C. (1998). Repensando os estudos sobre Representações e práticas em saúde/doença. Em P. C. Alves \& M. C. Rabelo (Orgs.), Antropologia da Saúde: Traçando Identidades e Explorando Fronteiras (pp.45-67). Rio de Janeiro: Editora Fiocruz/ Editora Relume Dumará.

Andrade, M. A. A. de (1998). A Identidade como representação e a representação da identidade. Em A. S. P. Moreira \& d. C. de Oliveira (Orgs.), Estudos Interdisciplinares de Representação Social (pp. 39-51). Goiânia: AB.

Berger, P. L. \& Luckmann, T. (1983). A Construção Social da Realidade: Tratado de Sociologia do Conhecimento. ( $\left.5^{\mathrm{a}} \mathrm{ed}.\right)$ Petropólis: Vozes. (Trabalho original publicado em 1966)

Borg, I. (1979). Some basic concepts of facet theory. Em J.C. Lingoes (Org.), Geometrical representation of relational data: Readings in multidimensional scaling (pp. 125-154). Ann Arbor: Mathesis Press.

Borg, I. (1993). How to construct indices in Facet Theory. Trabalho apresentado em 29 de agostoa 01 de setembro de 1993 da IV International Conference on Facet Theory, Praga, Czech Republic.

Canter, D. \& Kenny, C. (1981). The multivariate structure of design evaluation. Multivariate Behavioral Research, 16, 215-236.
Cohen, E. H. \& Amar, R. (1999). External Variables as Points in SSA: A Comparison with the Unfolding Techniques. Em R. Meyer Schweizer, D. Hänzi, B. Jann, E. Peier- Kläntschi \& H. J. Schweizer - Meyer (Orgs.), Facet Theory: Design and Analysis (pp. 259-279). Bern: FTA - Facet Theory Association (c/o Institut für Soziologie, Universität Bern).

Cohen, E. H. \& R. Amar (2002). External Variables as Points in Smallest Space Analysis: A Theoretical, Mathematical and Computer-Based Contribution. Bulletin de Methodologie Sociologique, 75, 40-56.

D' Andrade, R. (1995). Development of cognitive anthropology. Cambridge: Cambridge University Press.

Dancer, L. S. (1990). Introduction to facet theory and its applications. Applied Psychology: An International Review, 39(4), 365-377.

Doise, W., Clémence, A. \& Lorenzi-Cioldi, F. (1993). The quantitative analysis of social representations. Hemel Hempstead, Harvester Wheatscheaf.

Donald, I. (1985). The cylindrex of place evaluation. Em D. Canter (Org.), Facet Theory: Approaches to Social Research (pp. 165186). New York: Springer Verlag.

Duarte, L. F. D. (1986). Da Vida Nervosa nas Classes Trabalhadoras Urbanas. Rio de Janeiro: Zahar.

Duarte, L. F. D. (1994). A Outra Saúde: Mental, Psicossocial, Físico-Moral? Em P. C. Alves \& M. C. S. Minayo (Orgs.), Saúde e Doença: Um Olhar Antropológico (pp. 79-97). Rio de Janeiro: Ed. Fiocruz.

Durkheim, E. (1912). As formas elementares da vida religiosa: o sistema totêmico na Austrália. (P. Neves, Trad.). São Paulo: Martins Fontes.

Feger, H. \& Von Hecker, U. (1993). Testing the predictions of Facet Theory. Trabalho apresentado em 29 de agosta a 01 de setembro de 1993 da IV International Conference on Facet Theory, Praga, Czech Republic.

Frake, C. O. (1962). The ethnografic study of cognitive systems. Em T. Gladwin \& W. C. Sturtevant (Orgs.), Anthropology and Human Behavior (pp. 74-85). Washington: Anthropological Society of Washington.

Guareschi, P. A. (1995). Sem dinheiro não há salvação: ancorando o bem e o mal entre os pentecostais. Em P. A. Guareschi \& S. Jovchelovitch (Orgs.), Textos em representações sociais (pp.191205) ( $2^{\mathrm{a}}$ ed.). Petrópolis: Vozes.

Guttman, L. (1965). A General nonmetric technique for finding the smallest co-ordinate space for a configuration. Psychometrika, 33, 469-506.

Guttman, L. (1968). A general nonmetric technique for finding the smallest co-ordinate space for a configuration. Psychometrika, 33, 469-506.

Hita, M. G. (1998). Identidade feminina e nervoso: crises e trajetórias. Em P. C. Alves \& M. C. Rabelo (Orgs.), Antropologia da Saúde: Traçando Identidades e Explorando Fronteiras (pp. 102-133). Rio de Janeiro: Editora Fiocruz/ Relume Dumará.

Jodelet, D. (1989). Représentations sociales: Un domain en expansion. Em D. Jodelet (Org.), Les Représentations Sociales (pp. 31-61). Paris: Presses Universitaires de France.

Jovchelovitch, S. (2001). Representações Sociais: Saberes sociais e polifasia cognitiva. Curso de Extensão na FURB/PRORC, EDUCadernos - Série Estudos e Pesquisas, Blumenau, SC.

Lave, J. (1988). Cognition in practice. Cambridge: Cambridge Press. 
Levy, S. (1985). Lawful roles of Facets in Social Theories. Em D. Canter (Org.), Facet Theory: Approaches to Social Research (pp. 142-162). New York: Springer-Verlag.

Levy, S. (1993). Facet Theory: An overview of cumulative theory construction.Trabalho apresentado em 29 de agosto a 01 de setembro de 1993 IV International Conference on Facet Theory, Praga, Czech Republic, de 29 de Agosto a 01 de Setembro.

Minayo, M. C. (1995). O conceito de representações sociais dentro da sociologia clássica. Em P. A. Guareschi \& S. Jovchelovitch (Orgs.), Textos em representações sociais (pp.89-111) (2a ed.). Petrópolis: Vozes.

Moscovici, S. (1978). A Representação Social da Psicanálise. (A. Cabral, Trad). Rio de Janeiro: Zahar Editores.

Moscovici, S. (1989). Des représentations collectives aux représentations sociales. Em D. Jodelet(Org.), Les Représentations Sociales (pp. 62-86). Paris: Presses Universitaires de France.

Moscovici, S. (1996). L'êre des représentations sociales. Em W. Doise \& A. Palmonari (Orgs.), L'étude des représentations sociales (pp. 89-110). Lausane: Delachaux Niestlé.

Paula, R. F. \& Scott, R. P. (1985). Terapia Familiar: Duplo Vínculo e o Contexto Sócio-cultural do Recife. Jornal Brasileiro de Psiquiatria, 34(5), 327-336.

Roazzi, A. (1987a). O desenvolvimento individual, o contexto social e a prática de pesquisa. Psicologia: Ciência e Profissão, 3, 27-33.

Roazzi, A. (1987b). Pesquisa e Contexto: Métodos de investigação e diferenças sócio-culturais em questão. Cadernos de Pesquisa, 62, 35-44.

Roazzi, A. (1995). Categorização, formação de conceitos e processos de construção de mundo: Procedimento de classificações múltiplas para o estudo de sistemas conceituais e sua forma de análise através de métodos de análise multidimensionais. Cadernos de Psicologia, 1, 1-27.

Roazzi, A. (1999a). Pesquisa básica em Psicologia Cognitiva e sua relação com a psicologia social. Arquivos Brasileiros de Psicologia, 51(1), 23-54.

Roazzi, A. (1999b). Lar-doce-lar: Rainha ou rei? A representação da participação masculina nas tarefas domésticas e a lógica de sua distribuição em casais de nível sócio-econômico baixo. Arquivos Brasileiros de Psicologia. 51(4), 7-38.
Roazzi, A. \& Dias, M. G. B. B. (2001). Teoria das facetas e avaliação na pesquisa social transcultural: Explorações no estudo do juízo moral. Em Conselho Regional de Psicologia - 13a Região PB/RN (Org.), A diversidade da avaliação psicológica: Considerações teóricas e práticas (pp. 157-190). João Pessoa: Idéia.

Roazzi, A. Federicci, F. \& Carvalho, M.R. (1999). A facet approach to the study of fear in adults. Em R. Meyer-Schweizer, D. Hänzi, B. Jann, E. Peier-Kläntschi \& H. J. Schweizer-Meyer (Orgs.), Facet Theory: Design and Analysis (pp. 227-256). Bern: FTA Facet Theory Association (c/o Institut für Soziologie, Universität Bern).

Roazzi, A., Loureiro, C. \& Monteiro, C.M.G. (1996). Problemas psicossociais e influências na prática escolar: Investigações sobre vandalismo no contexto da escola pública. Em S.M. Wechsler (Org.), Psicologia escolar: Pesquisa, formação e prática (pp. 203-236). Campinas: Alínea Editora.

Roazzi, A. \& Monteiro, C. M. G. (1995). A representação social da mobilidade profissional em função de diferentes contextos urbanos e suas implicações para a evasão escolar. Arquivos Brasileiros de Psicologia, 47(3), 39-73.

Roazzi, A., Wilson, M. \& Federicci, F. (1995). Exploring the social representation of fear in children: A social class comparison. Em Joop J. Hox, Peter Swanborn \& G.J. Mellemberg (Orgs.), Facet Theory: Theory and content (pp. 122-1136). Zeist: SETOS.

Roazzi, A., Wilson, M. \& Federicci, F.C.B. (2001). A estrutura primitiva da representação social do medo. Psicologia: Reflexão e Crítica, 14(1), 57-72.

Russel, B. H. (1994). Research Methods in Anthropology: Qualitative and Quantitative Approaches. London: Sage.

Scott, Joan. (1996). Gênero: Uma categoria útil de análise histórica (C. R. Dabat \& M. B. Ávila, Trad). Recife: SOS Corpo.

Tyler, S. A. (1978). The said and the unsaid: Mind, Meaning and Culture. New York: Academic Press.

Young, F.W. (1987). Multidimensional scaling: History, theory and applications. Hillsdale: Erlbaum.

Recebido em 09.08.2006

Primeira decisão editorial em 13.12.2006

Versão final em 14.12.2006

Aceito em 21.01.2007 


\section{Apêndice}

Descrição das categorias: Tomou-se como referência, para apreensão dos significados dessas categorias, a contribuição de diversos autores, e em especial a de Duarte (1986):

Ataque: Foi tomado enquanto sintoma físico visto que, nessa condição, o sujeito apresenta muitas sensações em seu corpos considerados anormais ou incomuns no seu dia-a-dia, o que pode configurar-se como um quadro de doença. Segundo Duarte, o ataque é uma forma aguda de expressão do nervoso, tanto de sintomas físicos quanto morais, para ambos os gêneros visto que, a configuração desse conjunto de sintomas sofre uma avaliação moral sobre o seu comportamento, e que a forma de sua expressão também se diferencia entre os gêneros, dado o caráter de interioridade e privado da mulher, em oposição o caráter público e exterior do homem.

Caretas e tiques: Foram apreendidos como sintomas físicos, por apresentar em um caráter externo visível, no corpo, e pode-se entender que a sua associação a situação de doença é feita por uma certa relação com o que Duarte chama de caráter de condutibilidade dos nervos. As caretas e tiques representariam, assim, uma obstrução do fluxo normal de expressões de perturbação dos nervos, que são imaginados como fios condutores. $\mathrm{O}$ fato dessa categoria haver sido mais referida pelas mulheres pressupõe uma imagem de obstrução das expressões de perturbações por outras vias consideradas morais.

Choro: Foi apreendido enquanto sintoma físico pelo seu caráter exterior e a sua associação com outros sintomas físicos, como a dor de cabeça. A configuração de doença conforma-se sempre com o choro como reação ao desconforto. Em contrapartida, o choro é considerado como fenômeno moral, por se associar a idéia de fraqueza, de não resistência aos estímulos. Vale ressaltar que o fato dessa categoria apresentar diferenças significativas entre os gêneros legitima as orientações de condutas sexuais em nossa cultura como, "homem não chora".

Stress: Foi aqui visto sob seu aspecto de sintoma físico, por se considerar que a representação de doença está muito ligada ao corpo. O conteúdo dessa categoria denota uma aproximação dos limites suportáveis de suas forças físicas na realização de suas tarefas cotidianas, dentro dos seus critérios de normalidade e equilíbrio. Tanto homens quanto mulheres em suas tarefas diárias, como coloca Loyola (1984:126) "por estar a noção de saúde muito ligada a força - que a comida mantém e estimula - força utilizável no trabalho, único elemento que lhes fornece os meios de subsistência”. A contrapartida moral do stress seria assim a noção de fraqueza, principalmente por ser provocada pela fome. Ressalta-se que não houve diferenças significativas entre os gêneros na utilização dessa categoria, apesar da idéia de fraqueza física ser um atributo feminino, o que poderia levar a uma prevalência dessa categoria pelas mulheres.

Tremedeira: Tomado enquanto sintoma físico pelo aspecto característico de perda de controle sobre o corpo, como se ele se tornasse autônomo, sem obedecer a nenhum controle da vontade. Essa representação remete a imagem concreta dos fios de nervos dentro do corpo, concretos, pulsantes, como ressalta Duarte. Ao mesmo tempo apresenta uma dimensão moral de desequilíbrio postural sem diferenciação entre homens e mulheres.

Dores: Entendidas como experiências físicas desagradáveis, que compõem o quadro da doença. Segundo Duarte, as dores estão ligadas a representação de uma sensibilidade periférica dos nervos. Essa representação possui um peso simbólico significativo, por remeter-se também a perturbações morais, em expressões como "isso só me dá dor de cabeça". Essa categoria foi referida mais pelas mulheres do que pelos homens.

Náuseas: Um sintoma claro de desconforto físico, também componente do quadro de enfermidade que debilita o corpo. A náusea pode ser entendida sob o nódulo da comunicação nervosa referido por Duarte, em que se imagina que os nervos provocam movimentos, como nesse caso, de sair/entrar. Como uma intenção de saída de alguma coisa perturbadora do interior para o exterior, ou uma obstrução desse movimento de saída. Houve uma igualdade de referência dessa categoria entre os gêneros.

Insônia: Aqui entendida como sintoma físico pela sua repercussão comprometedora a todo o corpo. O sono, segundo Duarte, é central na qualificação da maior ou menor perturbação dos sujeitos, por ser comparado a paz, a calma, ao equilíbrio. A sua oposição ou sua ausência constante pode ser considerada como doença. Essa categoria não apresentou destaque significativo entre os gêneros.

Abandono: Referente às necessidades das relações afetivas, quebra de uma interação com pessoas próximas, como os familiares e o cônjuge. Esse tipo de resposta foi apresentado tanto por homens quanto por mulheres, no entanto, os homens fizeram esse tipo de referência em dobro. Englobou as expressões "solidão", "carência de afeto" e "traição amorosa". Essa categoria aponta para pelo menos dois caminhos: o primeiro diz respeito a questão cultural, que apresenta um julgamento de valor moral para o homem que é traído por sua mulher ou companheira, e o segundo parece refletir o estado de abandono em que são colocados os homens, pelas suas mulheres e filhos, como punição pela conduta empregada durante o convívio, em contrapartida, a solidão e o abandono em que se acham as mulheres, pela desvalorização de seus maridos.

Agitação: Referente as sensações, sentimentos e expressões do que as incomodam, reconhecidos em forma de comportamentos. Compôs-se das expressões: "agitação", "agressão", "impaciência", "irritação", "tensão", "mau humor", "palavrões", "pressão", "violência" e "tortura". Esse tipo de resposta apareceu em número semelhante para ambos os sexos. Muito característica da representação da doença dos nervos, a agitação remete a um rompimento dos critérios e normas estabelecidos pela noção de normalidade, ultrapassando os limites de tempo e espaço na comunicação social.

Medo: Referente aos sentimentos mais claros para as pessoas e que apontam para situações em que estas não conseguem vislumbrar possibilidades de mudanças. Constituiu-se das expressões: "medo", "angústia", "ansiedade", "apreensão", "de- 
pressão", "insegurança", "impressionado”, "intranqüilidade", "pavor", "raiva”, "revolta”, "tristeza” e "vergonha”. O gênero feminino apresentou um número de respostas maior que o dobro do número de resposta do gênero masculino. O medo, se tomado como uma reação defensiva a uma ameaça, aponta aqui, para uma situação de constante ameaça às mulheres.

Decepções: Referente as situações que apontam para o fim das possibilidades de mudança. A constatação de que nada vai mudar no sentido das expectativa criadas. Compôs-se das expressões: "decepções", "constrangimento" e "morte". Essa categoria apresenta respostas apenas femininas.

Nervoso: Parece haver aqui uma imagem global da doença, abarcando todos os sintomas, referente ao estado ou condição geral das pessoas, condizente com a identidade, segundo Duarte. Essa categoria apresentou número semelhante de respostas para ambos os gêneros e engloba as expressões "nervoso" e "nervosismo".

Doença: Referente a um estado mais interno da doença dos nervos, um estado permanente e distante dos demais, pela idéia de seu caráter irreversível. O número de respostas entre os gêneros nessa categoria, não apresentou diferenças significativas. Engloba as expressões "doença", "anormal", "debilidade mental", "doidice", "doido", "loucura".

Aperreio: Essa categoria possui um amplo espectro de sentidos. Aparece como referente às situações cotidianas e difíceis de serem enfrentadas no cuidado com a família, seja por carência de recursos materiais ou provindas dos relacionamentos conjugais, filiais e de vizinhança. Essa categoria englobou as expressões "aperreio", "perturbação" e "preocupação" e foi mais referida pelo gênero feminino. Alguns estudos, inclusive Duarte, associam o aperreio às mulheres, visto que o domínio doméstico se encontra eivado de relações interpessoais, o que pode provocar desentendimentos, ao mesmo tempo em que requer a administração feminina.

Descontrole: Referente a um estado mais temporário e ocasional, como que intermediário para se chegar a um estado de doença. Nessa categoria as respostas femininas aparecem em maior número, em relação às respostas masculinas, e está composta pelas expressões "descontrole", "desequilíbrio", "desespero" e "transtorno".

Necessidades: As respostas que compõem essa categoria foram mais fornecidas pelo sexo feminino. Pode-se associar esse dado a identificação das mulheres com a função e responsabilidade de cuidar dos filhos, dos doentes, da casa, da vida social e das tarefas inerentes a esse papel a elas atribuído. Essa categoria engloba as expressões: "necessidade de cuidado", "necessidade de paciência", "necessidade de remédio" e "necessidade de higiene".

Alcoolismo: Apesar do alcoolismo ser considerado tanto um problema físico quanto um problema moral, a dependência dessa droga foi considerada pelos sujeitos como causa da doença dos nervos. Essa categoria se compôs das expressões "alcoolismo" e "drogas". Apenas o gênero masculino forneceu esse tipo de resposta.

Ambiente: Algumas das respostas dessa categoria referem-se as dificuldades enfrentadas pelos sujeitos com a qualidade dos serviços prestados pelo Estado em sua comunidade e consequentemente a associação da falta de recursos básicos à sobrevivência como fatores causais da doença. Outras apontaram para as dificuldades de convivência com a vizinhança. Englobou as expressões "saúde", "sede", "moradia", "educação", "barulho" e "falta de respeito". O número de respostas para essa categoria foi semelhante para ambos os gêneros.

Situação financeira: Referente às condições de sobrevivência e de reprodução do grupo, essa categoria se diferencia da anterior por apresentar uma grande ênfase a questão do trabalho, para satisfação das necessidades básicas, conformando a noção de causa da doença dos nervos, pelo gênero masculino, que apresentou um número de respostas muito maior que o gênero feminino. Foi composta pelas expressões "situação financeira", "desemprego", "fome", "dificuldades", "miséria", "falta de remédio", "problemas".

Problemas de família: Refere-se às dificuldades constantemente enfrentadas no relacionamento familiar, os desentendimentos do cotidiano. Compõem essa categoria "os problemas de família" e as "brigas". O número de respostas entre os gêneros nessa categoria é semelhante, apresentando um leve destaque para o gênero masculino.

Nascença: Referente à noção de causalidade genética e/ou a hereditariedade de fatores provindos da situação e interação social. Nenhuma diferença entre os gêneros na visão dessa causa foi apresentada. 